ARTIGO ORIGINAL

ISSN 1677-5090

(C) 2019 Revista de Ciências Médicas e Biológicas

DOI: http://dx.doi.org/10.9771/cmbio.v18i2.33431

\title{
Avaliação micro e macroscópica de escovas dentais
}

\author{
Micro and macroscopic evaluation of toothbrushes
}

\author{
Gabriella Cordeiro Oliveira ${ }^{1}$, Maria Carolina Valdivino Soares ${ }^{1}$, Isla Camilla Carvalho Laureano ${ }^{2}$, \\ Lunna Farias ${ }^{2}$, Liege Helena Freitas Fernandes ${ }^{2}$, Cassiano Francisco Weege Nonaka ${ }^{3}$, Alessandro Leite \\ Cavalcanti ${ }^{3 *}$ \\ ${ }^{1}$ Graduanda em Odontologia, pela Universidade Estadual da Paraíba, UEPB; ${ }^{2}$ Doutoranda em Odontologia, pelo \\ Programa de Pós-Graduação em Odontologia, Universidade Estadual da Paraíba, UEPB; \\ ${ }^{3}$ Professor. Doutor do Programa de Pós-Graduação em Odontologia, Universidade Estadual da Paraíba, UEPB.
}

\begin{abstract}
Resumo
Introdução: as escovas dentais possuem como principal função a limpeza dos tecidos bucais. Objetivo: analisar as características micro e macroscópicas de escovas dentais de uso infantil e adulto. Metodologia: foram selecionadas 11 escovas dentais (cinco de uso infantil e seis de uso adulto). Dois pesquisadores treinados analisaram aspectos microcoscópicos e macroscópicos, de acordo com os parâmetros da Portaria $n^{\circ}$ 97/SVS (ANVISA). Os dados foram tabulados e analisados utilizando-se o Microsoft Excel, sendo apresentados por meio de estatística descritiva. Resultados: foram encontradas cerdas arredondadas em $40 \%$ das escovas de uso infantil e em $66,7 \%$ de uso adulto, com farpas em $60 \%$ das escovas de uso infantil e em $50 \%$ de uso adulto, com a parte ativa ovalada em $60 \%$ das escovas de uso infantil e em $50 \%$ de uso adulto e com as cerdas macias em $80 \%$ das escovas de uso infantil e em $50 \%$ de uso adulto. $O$ comprimento e a largura da parte ativa das de uso infantil variaram de 19,14 a $25,03 \mathrm{~mm}$ e de 8,82 a $13,98 \mathrm{~mm}$ respectivamente, enquanto, nas de uso adulto, o comprimento variou de 25,77 a $37,02 \mathrm{~mm}$ e a largura de 12,57 a $15,40 \mathrm{~mm}$. As escovas de uso infantil possuíam comprimento total entre 137,91 e 163,82 mm e as de uso adulto entre 180,08 mm e 195,42 mm. Conclusão: a maioria das escovas dentais analisadas não estão adequadas aos parâmetros estabelecidos na legislação brasileira, sendo essencial que o cirurgião-dentista oriente individualmente o paciente acerca de qual escova é a mais indicada.
\end{abstract}

Palavras-chave: Escovação Dentária. Higiene Bucal. Saúde Bucal.

\begin{abstract}
Introduction: toothbrushes have the main function of cleaning the oral tissues. Objective: to analyze the micro and macroscopic characteristics of children's and adult's toothbrushes. Methodology: eleven toothbrushes were selected (five for children and six for adults). Two trained researchers analyzed microscopic aspects and macroscopic aspects of the brushes, according to the parameters of Ordinance Number 97/SVS (ANVISA). Data were tabulated and analyzed by using Microsoft Excel and were presented by using descriptive statistics. Results: rounded bristles were found in $40 \%$ of the children's brushes and $66.7 \%$ of the adult, with barbs in $60 \%$ of the children's brushes and $50 \%$ of the adult, with the active part oval in $60 \%$ of the children's brushes and $50 \%$ adult brushes and soft bristles on $80 \%$ of the children's brushes and $50 \%$ of the adult. The length and width of the active part of the children's brushes ranged from 19.14 to $25.03 \mathrm{~mm}$ and from 8.82 to $13.98 \mathrm{~mm}$ respectively, while the adult brushes ranged from 25.77 to $37.02 \mathrm{~mm}$ in length and from 12.57 to $15.40 \mathrm{~mm}$ in width. The children's brushes had a total length between 137.91 and $163.82 \mathrm{~mm}$ and the adult brushes were between $180.08 \mathrm{~mm}$ and $195.42 \mathrm{~mm}$. Conclusion: most of the toothbrushes analyzed are not adequate by the parameters established by the Brazilian legislation, so it is essential that the dentist individually guide the patient as to which toothbrush is the most suitable.

Keywords: Toothbrushing. Oral Hygiene. Oral Health.
\end{abstract}

\section{INTRODUÇÃO}

A prevenção das doenças bucais mais comuns, como a cárie dentária e a doença periodontal, consiste na remoção mecânica adequada do biofilme dentário diariamente, sendo as escovas dentais o instrumento de higiene bucal mais amplamente adotado ${ }^{1,2}$.

As escovas dentais possuem como principal função a limpeza, de forma efetiva, dos tecidos da cavidade bucal. Contudo, a razão de escolha das escovas, pelos consumi-

Correspondente/Corresponding: *Alessandro Leite Cavalcanti - Universidade Estadual da Paraíba, Programa de Pós-graduação em Odontologia. - End: Rua das Baraúnas, S/N - Bodocongó, Campina Grande, PB CEP: 58429-500. - Tel.: (55) 83 3315-3326 -E-mail: alessandrouepb@ gmail.com dores, muitas vezes não abrange esses fatores e é, em geral, feita por questões pessoais ou financeiras, e não por um entendimento acerca da qualidade dos produtos ${ }^{3}$. As características das cerdas desses instrumentos, a força empregada pelo indivíduo, a técnica e os movimentos realizados na escovação dentária são fatores que podem resultar em traumas aos tecidos bucais 4 .

Existe uma grande variedade de escovas dentais disponíveis comercialmente no mercado brasileiro, o que gera a necessidade de aconselhamento profissional em relação ao melhor produto a ser adquirido. ${ }^{5}$ Dessa forma, é essencial que os cirurgiões-dentistas tenham conhecimento das características preferíveis desse instrumento, 
facilitando a escolha do produto para indicação adequada aos pacientes, de forma que não cause danos aos tecidos gengivais e dentários 5 .

No Brasil, as escovas dentais devem cumprir os parâmetros referentes aos seus aspectos micro e macroscópicos, estabelecidos pela Portaria $n^{\circ}$ 97/SVS, de 26 de junho de 1996 da Agência Nacional de Vigilância Sanitária $\left(\right.$ ANVISA) ${ }^{6}$. Entre os aspectos que devem ser analisados, encontram-se: o comprimento total mínimo, a largura máxima da parte ativa, o grau de rigidez das cerdas (macias, médias ou duras) e o formato das extremidades das cerdas (arredondadas, lisas, plumadas, planas ou polidas) ${ }^{6}$.

As cerdas arredondadas são as mais seguras e reduzem os danos aos tecidos bucais ${ }^{7}$. Sabe-se ainda que o uso de cerdas macias tem sido recomendado para promover a redução do biofilme e das lesões aos tecidos gengivais de modo que estudos envolvendo esses instrumentos são necessários para fornecer parâmetros aos cirurgiões-dentistas em relação à melhor indicação ${ }^{8}$. No entanto, é válido ressaltar que pesquisas analisando as características das escovas dentais disponíveis no mercado são escassas.

Face ao exposto, este estudo teve por objetivo analisar as características micro e macroscópicas de escovas dentais comercialmente disponíveis, segundo as especificações da Portaria no 97/SVS da ANVISA.

\section{METODOLOGIA}

\section{Desenho do Estudo}

Estudo descritivo, por meio da técnica de observação direta, por microscopia óptica de luz e por inspeção visual da embalagem e das características de escovas dentais.

\section{Amostra}

Foram utilizadas 11 escovas dentais, sendo cinco de uso infantil e seis de uso adulto (Quadro 1).

Quadro 1 - Escovas dentais de uso infantil e adulto utilizadas no estudo.

\begin{tabular}{|c|c|c|c|}
\hline \multicolumn{2}{|c|}{ Amostra } & Nome Comercial & Fabricante \\
\hline \multirow{5}{*}{ 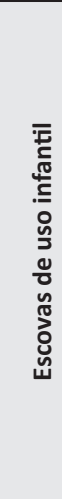 } & El1 & Johnson'sº́nión & \begin{tabular}{|l|} 
Johnson \& Johnson Inc, \\
New Jersey, Estados Unidos
\end{tabular} \\
\hline & EI2 & Inova Baby Elephant & $\begin{array}{l}\text { Superbrands Comércio de } \\
\text { Produtos de Uso Pessoal } \\
\text { Ltda, São Paulo, Brasil }\end{array}$ \\
\hline & EI3 & Colgate ${ }^{*}$ Dr. Dentuço & $\begin{array}{l}\text { Colgate-Palmolive } \\
\text { Company, Nova York, } \\
\text { Estados Unidos } \\
\end{array}$ \\
\hline & EI4 & Inova` KidsMonkey & $\begin{array}{l}\text { Superbrands Comércio de } \\
\text { Produtos de Uso Pessoal } \\
\text { Ltda, São Paulo, Brasil }\end{array}$ \\
\hline & EI5 & Dentrat $^{\circ}$ Girafa & $\begin{array}{l}\text { Vidal Life Ind. Com. de } \\
\text { Cosméticos Ltda, Paraná, } \\
\text { Brasil }\end{array}$ \\
\hline
\end{tabular}

\begin{tabular}{|c|c|c|c|}
\hline \multicolumn{2}{|c|}{ Amostra } & Nome Comercial & Fabricante \\
\hline \multirow{6}{*}{ 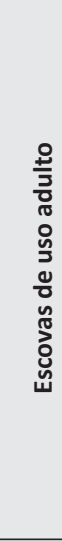 } & EA1 & $\begin{array}{l}\text { Sorriso } 0^{\circ} \text { Xtreme White } \\
5 \text { Estrelas }\end{array}$ & $\begin{array}{l}\text { Sorriso/Colgate-Palmolive } \\
\text { Company, Nova York, } \\
\text { Estados Unidos }\end{array}$ \\
\hline & EA2 & Even ${ }^{\circ}$ Plus & \begin{tabular}{|l|} 
Indústrias Reunidas \\
Raymundo da Fonte S/A, \\
Pernambuco, Brasil
\end{tabular} \\
\hline & EA3 & $\begin{array}{l}\text { Johnson's Reach Ultra } \\
\text { Clean }\end{array}$ & $\begin{array}{l}\text { Johnson \& Johnson Inc., } \\
\text { New Jersey, Estados Unidos }\end{array}$ \\
\hline & EA4 & Colgate ${ }^{\circ}$ Classic Clean & \begin{tabular}{|l} 
Colgate-Palmolive \\
Company, Nova York, \\
Estados Unidos \\
\end{tabular} \\
\hline & EA5 & $\begin{array}{l}\text { Oral-B Pró-Saúde An- } \\
\text { tibacteriana }\end{array}$ & $\begin{array}{l}\text { Procter \& Gamble Co, Ohio, } \\
\text { Estados Unidos }\end{array}$ \\
\hline & EA6 & $\begin{array}{l}\text { Curaprox } 5460 \text { Ultra } \\
\text { Soft }\end{array}$ & $\begin{array}{l}\text { Curaden International AG, } \\
\text { Kriens, Suíça }\end{array}$ \\
\hline
\end{tabular}

Fonte: Dados da pesquisa

\section{Análise Microscópica}

Foi realizada por dois pesquisadores previamente treinados. A preparação das amostras foi realizada por cortes com lâmina de bisturi (Swann Morton Ltda, Sheffield, United Kingdom) das cerdas das escovas, de forma que apenas a última fileira de tufos permanecesse. A análise microscópica foi executada por meio do microscópico Leica ICC50 W (Leica ICC50 W, Leica Microsystems $\mathrm{GmbH}$, Wetzlar, Alemanha). As extremidades das cerdas foram caracterizadas pelo formato (arredondadas ou não arredondadas) e pela presença ou ausência de farpas.

\section{Análise Macroscópica}

Consistiu na inspeção visual da embalagem e das características das escovas dentais. Foram avaliados o formato da parte ativa da escova (retangular, ovalado ou em "V"); a angulação do cabo da escova (reto ou angulado); a consistência das cerdas (macia, média ou extra-macia, segundo informação indicada na embalagem); o número de tufos; o tamanho das cerdas (foi medido em sua integralidade, cerdas e parte ativa da cabeça da escova em que elas são fixadas, e a porção presente da parte ativa foi então subtraída do valor encontrado. Além disso, haja vista que algumas escovas apresentavam cerdas em níveis diferentes, a medição foi realizada no local na qual elas apresentavam o maior comprimento. Determinado em $\mathrm{mm}$ ); a idade recomendada (para as escovas dentais infantis), descrita na embalagem do produto; as dimensões da parte ativa (comprimento e largura em $\mathrm{mm}$ ); e a medida do comprimento total da escova (em mm) (Figura 1).

As aferições foram realizadas utilizando-se um paquímetro (Paquímetro Universal, Mitutoyo Corporation, Kanagawa, Japão) para as variáveis tamanho das cerdas, dimensões da parte ativa e comprimento total da escova. Para as escovas adultas, que ultrapassavam a extensão máxima do paquímetro, aferiu-se o comprimento total através da soma entre as medidas 
do cabo da escova e o comprimento da parte ativa.

valores registrados e obtidas as médias.

As medidas foram realizadas em triplicata, sendo os

Figura 1 - Formato da Parte Ativa das Escovas: retangular (1a), ovalada (1b) ou em "V" (1c). Cabo sem angulação (2a) e angulado (2b). Dimensões da parte ativa (3a).
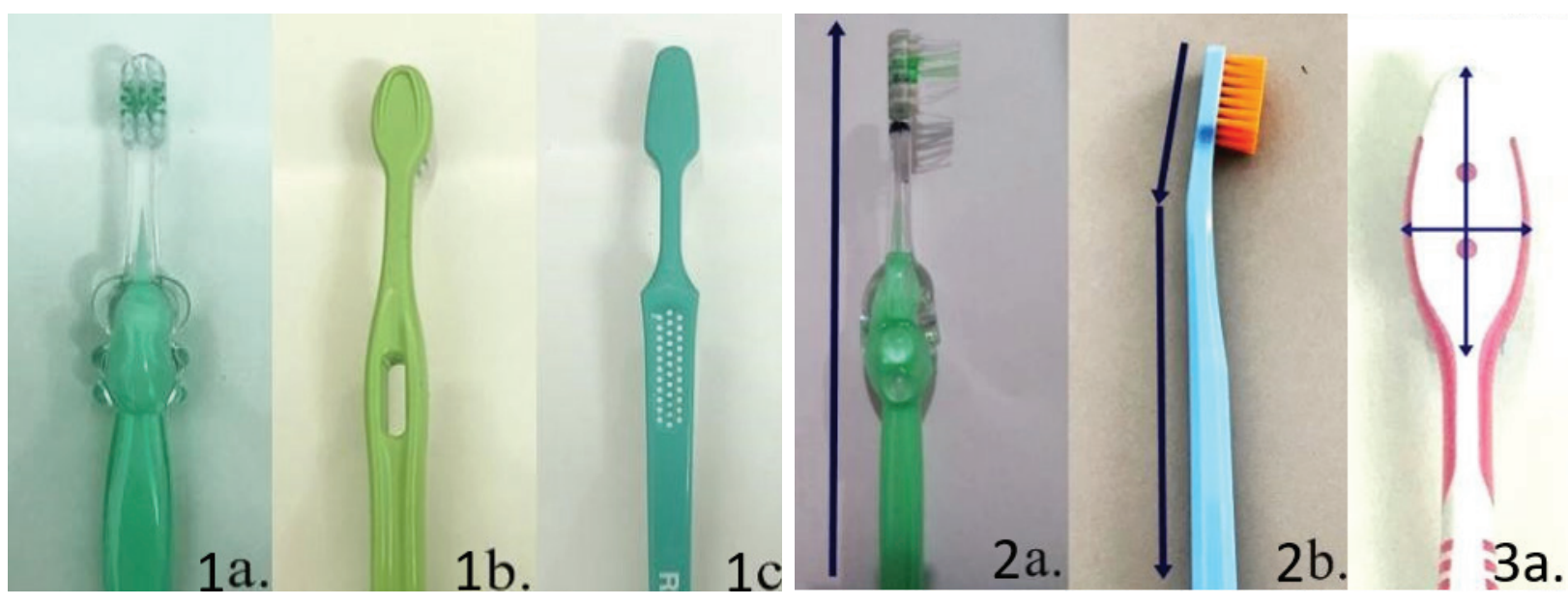

Fonte: Autoria própria

\section{Análise de Dados}

Os dados foram tabulados e analisados utilizando-se - Microsoft Excel 2016, sendo apresentados por meio de estatística descritiva (frequências absoluta e relativa, média e desvio-padrão).

\section{RESULTADOS}

A maior parte das escovas dentais de uso infantil apresentaram cerdas não arredondadas (60\%) e com presença de farpas (60\%) (Tabela 1; Figura 2). Com relação às características macroscópicas, houve predomínio do formato da parte ativa ovalada (60\%), do cabo angulado (80\%) e da consistência das cerdas macia (80\%). O número de tufos variou de 17 a 30. Além disso, a maioria das escovas não possuía a indicação da idade recomendada em sua embalagem (60\%) (Tabela 1).

Tabela 1 - Características gerais das escovas de uso infantil.

\begin{tabular}{|c|c|c|c|c|c|}
\hline Variáveis & El1 & EI2 & El3 & El4 & EI5 \\
\hline Formato das Cerdas & Arredondadas & Não arredondadas & Maioria arredondada & Não arredondadas & Não arredondadas \\
\hline Presença de Farpas & Sem farpas & Poucas farpas & Muitas farpas & Sem farpas & Poucas farpas \\
\hline Formato da Parte Ativa & Ovalada & Retangular & Ovalada & Ovalada & $E m$ "V" \\
\hline Angulação do Cabo & Angulado & Reto & Angulado & Angulado & Angulado \\
\hline Consistência das Cerdas & Macia & Macia & Extra-macia & Macia & Macia \\
\hline Número de Tufos & 27 & 17 & 28 & 29 & 30 \\
\hline $\begin{array}{l}\text { Idade } \\
\text { Recomendada }\end{array}$ & $\begin{array}{c}\text { Não indicada na } \\
\text { embalagem }\end{array}$ & Acima de 3 anos & Acima de 2 anos & $\begin{array}{c}\text { Não indicada na } \\
\text { embalagem }\end{array}$ & $\begin{array}{c}\text { Não indicada na } \\
\text { embalagem }\end{array}$ \\
\hline
\end{tabular}

Fonte: Dados da pesquisa

Com relação às escovas de uso adulto, a maior parte possuía formato das cerdas arredondadas $(66,7 \%)$, havendo ausência de farpas em $50 \%$ dos casos (Tabela 2; Figura 2). $\mathrm{Na}$ análise macroscópica, o formato da parte ativa ovalada foi encontrado em maior número (50\%), o cabo angulado foi constatado na sua totalidade (100\%) e as cerdas macias foram encontradas em $50 \%$ das escovas, havendo, ainda, uma escova com cerdas extra-macias. O número de tufos encontrados variou de 29 a 43 tufos (Tabela 2). 
Tabela 2 - Características gerais das escovas de uso adulto.

\begin{tabular}{lcccccc}
\hline Variáveis & EA1 & EA2 & EA3 & EA4 & EA5 & EA6 \\
\hline Formato das Cerdas & Arredondadas & Não arredondadas & Arredondadas & Arredondadas & Não arredondadas & Arredondadas \\
Presença de Farpas & Sem farpas & Poucas farpas & Sem farpas & Poucas farpas & Sem farpas & Poucas farpas \\
Formato da Parte Ativa & Ovalada & Ovalada & Em “V” & Em “V” & Ovalada & Retangular \\
Angulação do Cabo & Angulado & Angulado & Angulado & Angulado & Angulado & Angulado \\
Consistência das Cerdas & Macia & Macia & Média & Média & Macia & Ultra macia \\
Número de Tufos & 29 & 43 & 42 & 38 & 36 & 39 \\
\hline
\end{tabular}

Fonte: Dados da pesquisa

Figura 2 - Extremidade das Cerdas das Escovas Infantis (EI1-EI5) e Adultas (EA1-EA6).

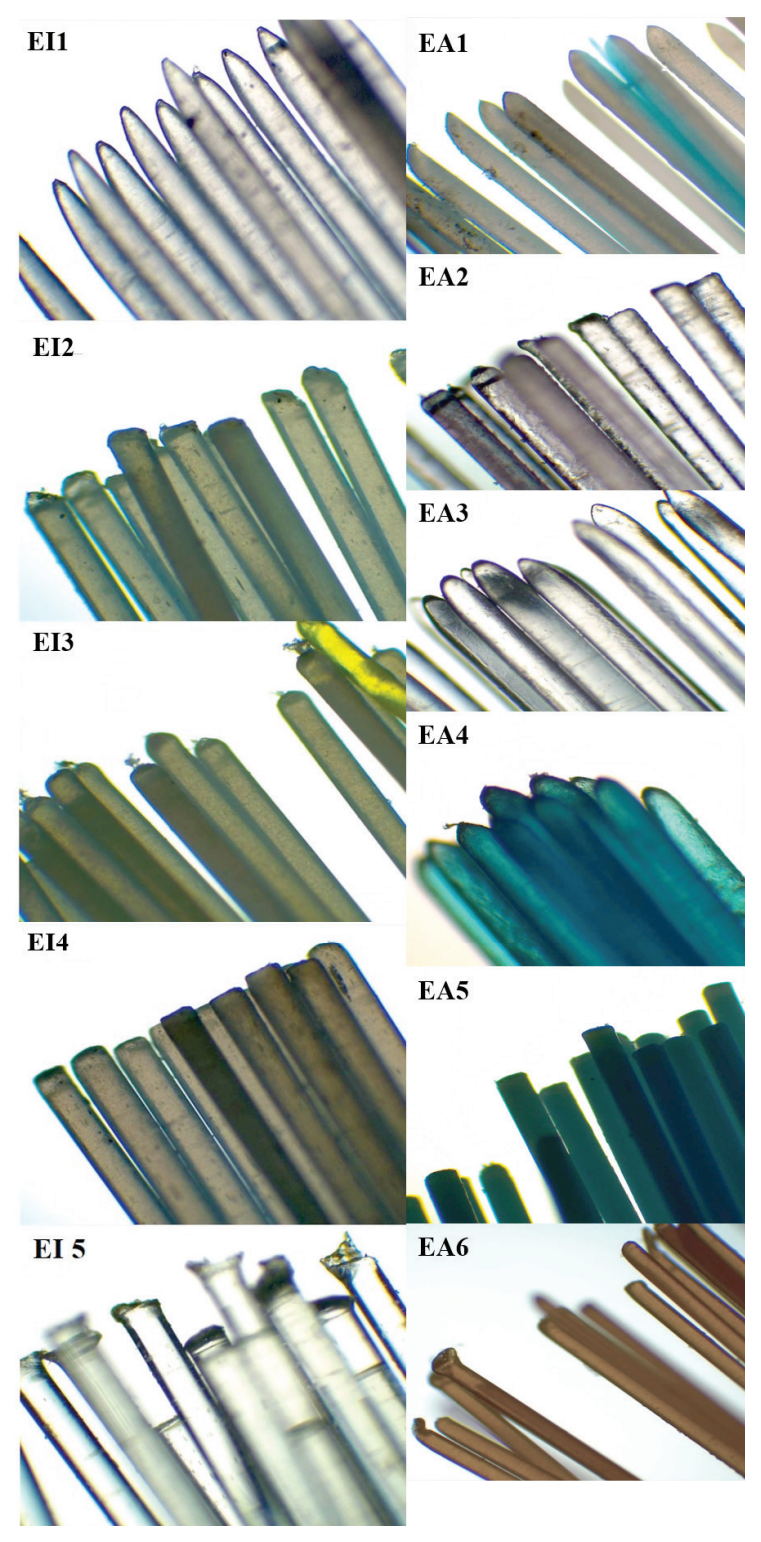

Fonte: Dados da pesquisa 
No que concerne às medidas das escovas dentais infantis, a média do tamanho das cerdas foi maior na EI5 $(10,79 \pm 0,17 \mathrm{~mm})$ e menor na EI2 $(9,80 \pm 0,17 \mathrm{~mm})$. Já para as dimensões da parte ativa, a El3 foi a que apresentou a maior média de largura $(13,98 \pm 0,12 \mathrm{~mm})$, sendo a El2 aquela com menor média $(8,82 \pm 0,04 \mathrm{~mm})$. A média de comprimento da parte ativa, por sua vez, foi maior na $\operatorname{EI5}(29,15 \pm 0,10 \mathrm{~mm})$ e menor na EI2 $(19,14 \pm 0,16 \mathrm{~mm})$. Com relação ao comprimento total, as médias da menor e da maior escova infantil possuíam respectivamente $137,91 \pm 0,13 \mathrm{~mm}$, na El2, e 163,82 $\pm 0,08 \mathrm{~mm}$, na El1 (Tabela 3).

Tabela 3 - Médias e desvios-padrão das escovas dentais de uso infantil (em $\mathrm{mm}$ ).

\begin{tabular}{lccccc}
\hline \multicolumn{1}{c}{ Variáveis } & $\begin{array}{c}\text { EI1 } \\
\text { Média (DP) }\end{array}$ & $\begin{array}{c}\text { EI2 } \\
\text { Média (DP) }\end{array}$ & $\begin{array}{c}\text { EI3 } \\
\text { Média (DP) }\end{array}$ & $\begin{array}{c}\text { EI4 } \\
\text { Média (DP) }\end{array}$ & $\begin{array}{c}\text { EI5 } \\
\text { Média (DP) }\end{array}$ \\
\hline $\begin{array}{l}\text { Tamanho das } \\
\text { Cerdas }\end{array}$ & $10,02 \pm 0,15$ & $9,80 \pm 0,17$ & $10,55 \pm 0,08$ & $10,17 \pm 0,19$ & $10,79 \pm 0,17$ \\
& Largura & Largura & Largura & Largura & Largura \\
Dimensões da & $12,70 \pm 0,06$ & $8,82 \pm 0,04$ & $13,98 \pm 0,12$ & $11,15 \pm 0,05$ & $11,45 \pm 0,05$ \\
Parte Ativa & Comprimento & Comprimento & Comprimento & Comprimento & Comprimento \\
& $24,97 \pm 0,08$ & $19,14 \pm 0,16$ & $24,98 \pm 0,16$ & $25,03 \pm 0,10$ & $29,15 \pm 0,10$ \\
Comprimento & $163,82 \pm 0,08$ & $137,91 \pm 0,13$ & $158,97 \pm 0,08$ & $149,50 \pm 0,09$ & $154,28 \pm 0,08$ \\
Total & & & & &
\end{tabular}

Fonte: Dados da pesquisa

A escova adulta que apresentou a maior média de tamanho das cerdas foi a EA4 (12,43 $\pm 0,05 \mathrm{~mm})$, enquanto a EA6 apresentou a menor média $(9,53 \pm 0,15 \mathrm{~mm})$. Quanto às dimensões da parte ativa, a maior média de largura encontrada foi a EA5 $(15,40 \pm 0,06 \mathrm{~mm})$ e a EA6 apresentou a menor média $(12,57 \pm 0,14 \mathrm{~mm})$. A média de comprimento da parte ativa, por sua vez, foi maior na $\operatorname{EA5}(37,02 \pm 0,19 \mathrm{~mm})$ e menor na $\operatorname{EA6}(25,77 \pm 0,12$ $\mathrm{mm})$. Para o comprimento total das escovas, a maior média encontrada foi a da EA5 (195,42 \pm 0,34 mm) e a menor média foi a da EA6 $(180,08 \pm 0,13 \mathrm{~mm})$ (Tabela 4).

Tabela 4 - Médias e desvios-padrão das escovas dentais de uso adulto (em $\mathrm{mm}$ ).

\begin{tabular}{|c|c|c|c|c|c|c|}
\hline Variáveis & EA1 & EA2 & EA3 & EA4 & EA5 & EA6 \\
\hline & Média (DP) & Média (DP) & Média (DP) & Média (DP) & Média (DP) & Média (DP) \\
\hline \multirow[t]{2}{*}{$\begin{array}{l}\text { Tamanho das } \\
\text { Cerdas }\end{array}$} & $12,05 \pm 0,14$ & $10,62 \pm 0,08$ & $11,56 \pm 0,18$ & $12,43 \pm 0,05$ & $11,60 \pm 0,18$ & $9,53 \pm 0,15$ \\
\hline & Largura & Largura & Largura & Largura & Largura & Largura \\
\hline \multirow{3}{*}{$\begin{array}{l}\text { Dimensões da } \\
\text { Parte Ativa }\end{array}$} & $15,00 \pm 0,06$ & $13,35 \pm 0,16$ & $14,20 \pm 0,19$ & $14,20 \pm 0,09$ & $15,40 \pm 0,06$ & $12,57 \pm 0,14$ \\
\hline & Comprimento & Comprimento & Comprimento & Comprimento & Comprimento & Comprimento \\
\hline & $33,75 \pm 0,10$ & $32,50 \pm 0,13$ & $35,93 \pm 0,16$ & $32,53 \pm 0,31$ & $37,02 \pm 0,19$ & $25,77 \pm 0,12$ \\
\hline $\begin{array}{l}\text { Comprimento } \\
\text { Total }\end{array}$ & $189,37 \pm 0,21$ & $186,10 \pm 0,13$ & $187,53 \pm 0,18$ & $185,15 \pm 0,10$ & $195,42 \pm 0,34$ & $180,08 \pm 0,13$ \\
\hline
\end{tabular}

Fonte: Dados da pesquisa

\section{DISCUSSÃO}

Atualmente, existem disponíveis no mercado, escovas dentais com características variadas ${ }^{9}$. Esses instrumentos de higiene podem possuir formas, tamanhos, desenhos, cabos, cerdas e cabeças diversos ${ }^{10}$. Tendo em vista que as características das cerdas podem causar traumas aos tecidos moles e duros durante a escovação ${ }^{4}$, e que o design geral da cabeça da escova tem relação com a eficácia e a segurança da limpeza da cavidade bucal ${ }^{7}$, justifica-se a importância de analisar os produtos comercialmente disponíveis, para que os fabricantes possam produzir escovas com melhores qualificações técnicas; e para os consumidores, para que façam uma escolha adequada para manutenção de sua higiene bucal ${ }^{11}$.

No que se refere às cerdas das escovas, pode-se afirmar que estas são os componentes mais importantes, uma vez que entram em contato diretamente com os tecidos que compõem a cavidade oral e que são elas que determinam as principais características das escovas ${ }^{12}$. Uma das características das cerdas é o tipo de acabamento. Nesse sentido, ter extremidade arredondada é um fator importante na proteção dos tecidos dentários e gengivais, já que estão relacionadas à menor incidência de abrasões dentárias e recessões gengivais ${ }^{13}$. Além disso, esse tipo de acabamento remove mais biofilme das superfícies dentárias, sendo mais eficaz na redução do sangramento gengival ${ }^{14}$. Existem evidências de que as cerdas retas, sem acabamento, causam mais danos aos tecidos duros e moles ${ }^{14}$. Todavia, mesmo com esses benefícios advindos do arredondamento das extremidades das cerdas, $60 \%$ das escovas de uso infantil e $33,3 \%$ das escovas de uso adulto possuíam extremidades não arredondadas, apresentando-se, portanto, inadequadas quanto ao parâ- 
metro analisado, tendo em vista os danos que podem ser causados pelas cerdas retas sem o correto acabamento.

Além do critério de arredondamento das extremidades das cerdas, preconiza-se que estas não devem possuir farpas, prevenindo danos aos tecidos dentários e gengivais ${ }^{4}$. Em relação a esse aspecto, foram encontradas farpas na maioria das escovas de uso infantil, corroborando achados prévios ${ }^{4}$. De modo semelhante, metade das escovas de uso adulto também apresentaram farpas. Esse fator influencia em uma escovação que causa mais danos aos tecidos orais e pode ser evitado com o acabamento das cerdas das escovas em formato arredondado?.

Com relação à consistência das cerdas, escovas com cerdas de dureza média e alta removem mais biofilme do que as escovas macias, embora causem maior abrasão gengival e sejam um fator de risco significativo para a incidência de fissuras gengivais ${ }^{14}$. Além disso, podem provocar maior ocorrência de traumatismo nos tecidos moles em comparação com as escovas com cerdas mais macias ${ }^{15}$.

Neste estudo, todas as escovas de uso infantil satisfizeram o requisito de apresentar cerdas macias, com uma delas apresentando cerdas extra-macias. É válido ressaltar que, pelo fato de a gengiva infantil ser mais delgada, ela acaba sendo mais suscetível aos danos mecânicos provenientes da escovação, o que faz com que as escovas macias sejam as mais apropriadas para as crianças ${ }^{10}$. Já no que se refere às escovas de uso adulto, embora a maioria tenha apresentado cerdas macias e extra-macias, um terço delas possuíam cerdas de comprimento médio e, portanto, não podem ser consideradas tão satisfatórias no que concerne a este requisito.

No tocante ao formato da parte ativa, áreas com formato retangular sofrem maior desgaste ${ }^{16}$. No caso deste estudo, $20 \%$ das escovas de uso infantil tinham cabeça retangular. Por sua vez, nas escovas de uso adulto, apenas uma apresentava formato retangular, porém possuía suas bordas arredondadas.

No que concerne às dimensões da parte ativa, a largura máxima estabelecida pela legislação brasileira ${ }^{6}$, deve ser de $12 \mathrm{~mm}$ na escova de uso infantil e de $16 \mathrm{~mm}$ na escova de uso adulto. Com base nos resultados obtidos, apesar de as escovas de uso adulto se enquadrarem nesse requisito, observou-se que $40 \%$ das escovas de uso infantil ultrapassaram os parâmetros estabelecidos. A escova dental deve ser de fácil uso e deve atingir todas as superfícies dos dentes ${ }^{17}$.

Quanto ao comprimento da parte ativa, a Portaria no 97/SVS ${ }^{6}$ não estabelece um valor a ser adotado pelos fabricantes para o comprimento de nenhum dos tipos de escova. Por esse motivo, as medidas recomendadas variam em alguns estudos ${ }^{11,12}$ e não há padronização estabelecida, tornando difícil a avaliação de uma escova como adequada ou não para este parâmetro. Zaze et al. ${ }^{12}$ indicaram, por exemplo, que o comprimento da cabeça de uma escova de uso infantil ou adulto deve ser compreendido entre 25 e $32 \mathrm{~mm}$, enquanto para Sasan et al..$^{11}$ esse valor deve ser entre 25,4 e $35,8 \mathrm{~mm}$.
Nesta pesquisa, para as escovas de uso infantil as médias dos comprimentos encontrados variaram de 19,14 $\mathrm{mm}$ a $29,15 \mathrm{~mm}$. Assim, segundo o parâmetro estabelecido por Zaze et al. ${ }^{12}, 60 \%$ das escovas não atingiram o comprimento mínimo determinado, enquanto, seguindo os valores indicados por Sasan et al. ${ }^{11}$, apenas uma das escovas apresentou comprimento conforme o sugerido. Nas escovas de uso adulto, pôde-se verificar que os valores encontrados variaram de $25,77 \mathrm{~mm}$ a $37,02 \mathrm{~mm}$. Seguindo o parâmetro citado por Zaze et al. ${ }^{12}$, todas as escovas, à exceção da EA6, ultrapassaram o comprimento máximo indicado. Segundo os valores indicados por Sasan et al. ${ }^{11}$, por sua vez, $33,3 \%$ das escovas apresentaram comprimento da cabeça maior que o sugerido. Nesse sentido, escovas com parte ativa menor têm maior alcance e possuem a vantagem de garantir uma maior remoção de biofilme, especialmente nas áreas do segundo e terceiro molares ${ }^{11}$.

Considerando o número de tufos da parte ativa, foi observado uma variabilidade com relação a sua quantidade, mostrando que não há uma padronização 4 . De acordo com Zaze et al..$^{12}$, as escovas devem apresentar 18 ou 24 tufos, o que demonstra que as escovas de uso infantil não se enquadram nessa recomendação, apresentando uma escova (20\%) com tufos abaixo do número recomendado e quatro escovas (80\%) com tufos acima do número recomendado. As escovas de uso adulto também não seguem esse parâmetro, visto que a totalidade dos produtos analisados apresentaram número de tufos acima do recomendado.

No que se refere à angulação, o cabo da escova deve ser reto e volumoso, para facilitar a empunhadura e o acesso à cavidade bucal, além de proporcionar uma remoção do biofilme dentário mais eficiente ${ }^{12}$. Entretanto, foi verificado que apenas $20 \%$ das escovas de uso infantil apresentaram cabo reto, enquanto nenhuma escova de uso adulto possuía essa característica.

Para o comprimento das cerdas da escova, é indicado que, no caso das escovas de uso infantil, este não exceda os $10 \mathrm{~mm}$ de extensão, a fim de melhor se acomodar na cavidade bucal da criança ${ }^{10}$. Um comprimento excessivo pode influenciar no aumento da quantidade de dentifrício utilizado na escovação, gerando maior risco de a criança deglutir cremes dentais fluoretados e, consequentemente, aumentar a ocorrência de fluorose dentária ${ }^{10}$.

A maioria das escovas analisadas no estudo ultrapassaram o comprimento das cerdas recomendado, evidenciando, assim, a falta de adequação. Já nas escovas adultas, por sua vez, a variação foi entre $9,53 \mathrm{~mm}$ e $12,43 \mathrm{~mm}$. Em relação a essa característica, não consta na Portaria no 97 da ANVISA um valor limite para essa medida ${ }^{6}$. Entretanto, é descrito na literatura algumas recomendações quanto a esse parâmetro. De acordo com Zaze et $a . .^{12}$, para o tamanho das cerdas dessas escovas, o requisito é que este apresente comprimento uniforme, a fim de promover um contato e uma ação simultânea das cerdas, somado a uma pressão uniforme; algo que só foi verificado em uma única escova de uso adulto. 
De acordo com a Portaria da $\mathrm{ANVISA}^{6}$, o comprimento total mínimo da escova de uso infantil deve ser de $100 \mathrm{~mm}$, enquanto o da escova de uso adulto deve ser de 150 mm, não havendo, entretanto, limite máximo de comprimento. Neste estudo, todas as escovas, de uso infantil e adulto, estavam em conformidade com a supracitada Portaria.

Nesta pesquisa foi também observado que a maioria das escovas de uso infantil (60\%) não indicava na embalagem para qual faixa etária o produto era indicado. A ausência dessa indicação pode fazer com que os pais e responsáveis, no momento da escolha do produto, acabem adquirindo uma escova com características não adequadas para a faixa etária proposta, o que pode dificultar o ato da escovação e trazer danos aos tecidos dentais e gengivais. Evidencia-se também a falta de cuidado dos fabricantes, ao confeccionarem as escovas sem direcioná-las para a faixa etária correta ${ }^{4}$.

Como limitações do estudo, tem-se a seleção da amostra por conveniência, a não avaliação das escovas de todas as marcas disponíveis no mercado brasileiro e a análise de apenas uma escova de cada modelo, podendo as alterações serem provenientes de falhas de um lote específico. A despeito desses aspectos, os resultados obtidos demonstram que não há uma escova dentária que apresente todas as características consideradas ideais.

Dessa forma, com uma ampla gama de escovas dentais disponíveis no mercado, sem o correto auxílio do cirurgião-dentista, o paciente pode fazer escolhas inadequadas, o que torna necessária a orientação profissional ${ }^{18}$. Portanto, é essencial a realização de estudos que propiciem comparações entre os diversos produtos e marcas comerciais ${ }^{8}$, a fim de que as falhas técnicas existentes possam ser devidamente corrigidas.

\section{CONCLUSÃO}

As escovas dentais analisadas apresentaram grande diversidade em suas características, com maioria dos produtos de uso infantil apresentando cerdas não arredondadas, presença de farpas, ausência da indicação da idade recomendada na embalagem, comprimento da parte ativa menor que o mínimo estabelecido e com o número de tufos, a angulação e o comprimento das cerdas inadequados. Já para as escovas de uso adulto, constatou-se a presença de farpas em metade das amostras, número de tufos acima do recomendado e a angulação e o comprimento das cerdas inapropriados.

\section{REFERÊNCIAS}

1. SUNNY, N. et al. Effects of Bristle Hardness \& Duration of Manual Tooth brushing on Plaque Control. Indian J. Comm. Health, Uttarakhand, n. 29, v. 1, p. 123-128, Jan. 2017.
2. GROVER, D. et al. Toothbrush: 'A key to mechanical plaque control'. Indian J. Oral Sci., Gulabgarh, v. 3, n. 3, p. 62-68, Jan. 2012.

3. VERSTEEG, P. et al. Evaluation of two soft manual toothbrushes with different filament designs in relation to gingival abrasion and plaque removing efficacy. Int. J. Dent. Hyg.,Oxford, v. 6, n. 3, p. 166-173, Aug. 2008.

4. LEITE, D. et al. Análise micro e macroscópica de instrumento de higiene oral: caracterização das escovas dentais. Rev. Bras. Ciênc. Saúde, João Pessoa, v. 16, n. 4, p. 531-536, dez. 2012.

5. MOREIRA, V. G. et al. Parâmetros morfológicos de escovas dentais comercializadas em João Pessoa-PB. Int. J. Dent., Recife, n. 9, v. 4, p. 169-173, out./dez. 2010.

6. BRASIL. Ministério da Saúde. Secretaria de Vigilância Sanitária. Portaria no 97, de 26 de junho de 1996. Especifica os requisitos para escovas dentais de uso geral expostas ao consumo no Brasil. Diário Oficial [da] União. Brasília, DF, 27 jun. 1996. Seção 1.

7. VOELKER, M. A. et al. Catalogue of toothbrush head designs. J. Dent. Hyg., Chicago, v. 83, n. 3, p. 118-133, June 2013.

8. ROSING, C. K. et al. Efficacy of two soft-bristle toothbrushes in plaque removal: a randomized controlled trial. Braz Oral Res., São Paulo, v. 30, n.1, p. 1-6, Nov. 2016

9. KUMAR, S. et al. Comparison of surface abrasion produced on the enamel surface by a standard dentifrice using three different toothbrush bristle designs: a profilometric in vitro study. J. Conserv. Dent., Amritsar, v. 17, n. 4, p. 369-373, July/Aug. 2014.

10. FEITOSA, N. B. et al. Avaliação da apresentação comercial de escovas dentais disponíveis no Brasil. Ver. Odonto. Ciênc., Porto Alegre, v. 23, n. 1, p. $77-81,2008$

11. SASAN, D. et al. Toothbrush selection: a dilemma? Indian J. Dent. Res., Ahmedabad, v. 17, n. 4, p. 167-170, Oct./Dec. 2006.

12. ZAZE, A. C. S. F. et al. Eficácia de diferentes tipos de escovas dentais na remoção do biofilme bucal. Arq. Cienc. Saúde UNIPAR., Umuarama, v. 20, n. 2, p. 101-109, maio/ago. 2016.

13. OLIVEIRA, G. J. P. L. de et al. Effect of toothbrushing with different manual toothbrushes on the shear bond strength of orthodontic brackets. Braz. Oral Res., São Paulo, v. 24, n. 3, p. 316-322, July/Sept. 2010.

14. CAPOROSSI, L. S. et al. Combined effect of end-rounded versus tapered bristles and a dentifrice on plaque removal and gingival abrasion. Braz. Oral Res., São Paulo, v. 30, n. 1, p. 1-11, Mar. 2016.

15. ZIMMER, S. et al. Cleaning efficacy and soft tissue trauma after use of manual toothbrushes with different bristle stiffness. J. Periodontol., Chicago, v. 82, n. 2, p. 267-271, Feb. 2011.

16. MULLER-BOLLA, M. et al. Manual toothbrush wear and consequences on plaque removal. J. Clin. Dent., Yardley PA, v. 18, n. 3, p. 73-78, 2007.

17. $\mathrm{CHOI}, \mathrm{Y}$. J. et al. A study on toothbrush wear index and wear rate in some kindergarten children. Curr. Pediatr. Rev., Sharjah, v. 21, n. 4, p. 577-581, 2017

18. BOTTAN, E. R. et al. Critérios adotados para a escolha da escova dental: estudo com consumidores de Florianópolis, Santa Catarina (Brasil). RSBO, Joinville, v. 7, n. 2, p. 173-181, jun. 2010.

Submetido em: 04/09/2019

Aceito em: 16/09/2019 